\title{
Increased $B C R$ promoter DNA methylation status strongly correlates with favorable response to imatinib in chronic myeloid leukemia patients
}

\author{
YOUNGIL KOH $^{1}$, DAE-YOUNG KIM ${ }^{2,3}$, SUNG-HYO PARK ${ }^{4}$, HYANG-MIN BYUN ${ }^{6}$, INHO KIM ${ }^{1,3,4}$, \\ SUNG-SOO YOON ${ }^{1,3}$, BYOUNG KOOK KIM ${ }^{1,3}$, EUNKYUNG PARK ${ }^{3,5}$, \\ ALLEN S. YANG ${ }^{6}$ and SEONYANG PARK ${ }^{1,3,4}$

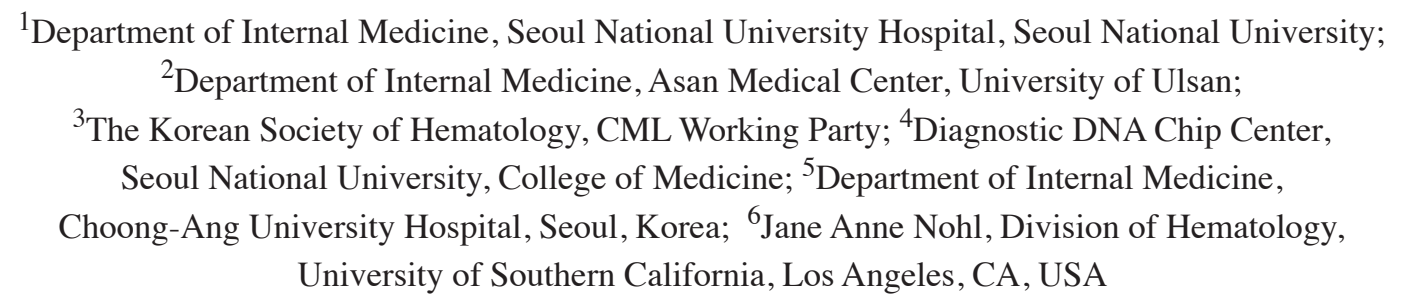

Received June 17, 2010; Accepted November 16, 2010

DOI: $10.3892 / \mathrm{ol} .2010 .208$

\begin{abstract}
To define the correlation between $B C R$ promoter DNA methylation and response to imatinib in chronic myeloid leukemia (CML), we investigated $B C R$ promoter DNA methylation in three groups of subjects. The first group included chronic phase patients enrolled in an imatinib dose escalation trial. In the trial, patients who failed to achieve optimal response with $400 \mathrm{mg} /$ day (suboptimal responders) received an escalated imatinib dose. The level of $B C R$ promoter DNA methylation was quantitated at baseline six months after dose escalation. The second group included patients who achieved complete cytogenetic remission after receiving $400 \mathrm{mg} /$ day of imatinib (optimal responders), and the third group were the healthy controls. In the suboptimal responders, an increased $B C R$ promoter DNA methylation at six months compared with the baseline was related to a rapid reduction in the $B C R-A B L / A B L$ transcript level following dose escalation $(\mathrm{p}=0.001)$ and a longer time to treatment failure (TTFx) of the dose-escalated imatinib $(p=0.008)$. When multivariate analysis was performed with regard to the baseline $B C R-A B L$ transcript level, baseline $B C R$ promoter DNA methylation, and a change in the $B C R$ promoter DNA methylation following dose escalation, the increase in the $B C R$ promoter DNA methylation following dose escalation
\end{abstract}

Correspondence to: Professor Seonyang Park, Department of Internal Medicine, Seoul National University Hospital, 101 Daehagro, Jongno-gu, Seoul 110-744, Republic of Korea

E-mail: seonpark@plaza.snu.ac.kr

Key words: chronic myelogenous leukemia, imatinib, methylation, $B C R$ was an independent predictive factor for TTFx of doseescalated imatinib (hazard ratio, 0.294; $\mathrm{p}=0.015$ ). The baseline $B C R$ promoter DNA methylation level in the suboptimal responders was lower than that in $B C R$ promoter DNA methylation in the optimal responders $(\mathrm{p}=0.001)$ and healthy controls $(\mathrm{p}<0.001)$. In both the optimal and suboptimal responders, $B C R$ promoter DNA methylation had an inverse correlation with the duration of the $400 \mathrm{mg} /$ day imatinib use. In conclusion, increased $B C R$ promoter DNA methylation strongly correlates with a more favorable imatinib response in CML patients.

\section{Introduction}

Chronic myeloid leukemia (CML) is a clonal stem cell disease with deregulated tyrosine kinase activity of $B C R-A B L$. $B C R-A B L$ can be targeted by drugs, and various tyrosine kinase inhibitors (TKIs) are effective in the treatment of CML. From a genetic viewpoint, although the cascade of events following $B C R-A B L$ oncogene transcription that leads to $C M L$ is actively being investigated $(1,2)$, the manner in which $A B L$ kinase activity is increased by $B C R$ at the genetic level is not clearly understood (3-5). The promoter region that plays a key role in the transcription of $B C R-A B L$ remains to be elucidated. $A B L$ is regulated by two promoter regions, one of which is $\mathrm{Pa}$. $\mathrm{Pa}$ is conserved in the case of fusion with $B C R$, but the methylation status of $\mathrm{Pa}$ does not correlate with disease status in CML $(6,7)$. Instead, $A B L$ activity is thought to be modulated by the $B C R$ promoter $(8,9)$, and $B C R$ promoter DNA methylation is a proposed mechanism for transcription control in CML (10). The methylation status of the $B C R$ promoter, however, has rarely been investigated in CML. If $B C R$ promoter DNA methylation actually controls transcription of the $B C R-A B L$ fusion gene in CML, then the methylation status of the $B C R$ promoter should exhibit a correlation with disease status. Furthermore, 
the methylation status of $B C R$ may also be used as a predictive marker during tyrosine kinase inhibitor (TKI) therapy.

Imatinib (Gleevec ${ }^{\circledR}$; Novartis, Basel, Switzerland) is the most commonly used TKI therapy for all phases of CML [chronic phase (CP), accelerated phase (AP) and blast crisis (BC)] (11). Approximately $10-15 \%$ of CML patients treated with imatinib as first-line therapy suffer disease progression (12). Furthermore, imatinib is associated with secondary resistance $(13,14)$. For patients who fail to respond to first-line standard dose imatinib therapy, dose-escalated imatinib is a reasonable option, along with second generation TKIs. We previously performed a prospective multi-center single-arm phase IV study in which escalated doses of imatinib were administered to Korean patients who had less than optimal response to the standard dose imatinib (15). The present study demonstrated considerable efficacy of dose-escalated imatinib in CML patients, showing suboptimal response to standard dose imatinib. Moreover, early molecular response, defined as a reduction in the $B C R-A B L / A B L$ ratio by more than $50 \%$ within 6 months, was found to be a surrogate marker for longterm response. On the other hand, the $B C R-A B L$ mutation rate was relatively low in the suboptimal responders to imatinib, and the mutation status did not affect the outcome of escalated dose imatinib therapy.

Consequently, $B C R$ promoter DNA methylation analysis was performed i) to reveal the role of the $B C R$ promoter in the transcriptional control of the $B C R-A B L$ fusion gene, and ii) to investigate epigenetic predictive markers for response and long-term outcome of imatinib dose escalation treatment. For further comparison, $B C R$ promoter DNA methylation status was analyzed in another two groups. The second group included patients who achieved complete cytogenetic remission after receiving $400 \mathrm{mg} /$ day imatinib (optimal responders) and the third group were healthy controls.

\section{Materials and methods}

Study population. A total of 71 Korean patients from 19 centers in Korea were enrolled in this study between 2005 and 2006. The $B C R$ promoter DNA methylation status was evaluated in three groups of subjects. The first group comprised CP CML patients enrolled in the imatinib dose escalation study. The study design and results of this imatinib dose escalation trial were described elsewhere (15). Briefly, this open-label, singlearm, multi-center phase IV study enrolled CML patients between 15 and 75 years of age with adequate organ function. Patients in CP with a less than optimal response to standard dose imatinib were included. Patients in AP or BC who failed to achieve complete hematologic response after 3 months of imatinib were also eligible. Those patients who experienced more than grade 2 adverse events to the standard imatinib dose were excluded. Imatinib was administered orally at $600 \mathrm{mg}$ / day for $\mathrm{CP}$ patients. Escalation to $800 \mathrm{mg} /$ day imatinib was permitted for patients in AP or BC. Patients received doseescalated imatinib for at least 12 months or until progressive disease or intolerable toxicity occurred. Cytogenetic response (CyR) was assessed every 6 months. Molecular response (MR) was assessed every 3 months with standardized $B C R-A B L / A B L$ of a peripheral blood or bone marrow aspirate using real-time reverse transcription quantitative $\mathrm{PCR}$. The criterion for time to treatment failure (TTFx) followed the criterion advocated by LeukemiaNET (11). A baseline $B C R$ - $A B L$ gene mutation test was performed using matrix-assisted laser desorption/ ionization time of flight mass spectrometry.

The second group, treated at Seoul National University Hospital, comprised CML patients who achieved complete CyR with the standard dose imatinib (300 or $400 \mathrm{mg} /$ day; optimal responders). The patients did not previously experience dose-escalated imatinib and were required to be in complete cytogenetic response (CCyR) at the time of blood sampling. The duration of the standard dose imatinib was evaluated. Written informed consent was obtained from all patients.

The third group included healthy individuals who exhibited no evidence of any disease. Healthy controls willing to donate a blood sample with informed consent were included. The study of $B C R$ promoter DNA methylation in the second and third group of patients was approved by the Institutional Review Board of Seoul National University Hospital.

DNA preparation for BCR promoter DNA methylation. The methylation of the $B C R$ promoter was assessed in $37 \mathrm{CP}$ CML patients whose samples were available at baseline and 6 months after imatinib dose escalation. Additionally, $B C R$ promoter DNA methylation status was evaluated in 29 optimal responders and 39 healthy controls. Genomic DNA was extracted from patient blood using the DNeasy ${ }^{\circledR}$ Blood and Tissue kit (Qiagen, Hilden, Germany). Gender-matched human genomic DNA (Promega, Madison, WI, USA) was used as reference DNA. Extracted DNA was quantified using a NanoDrop ND-1000 spectrophotometer (NanoDrop Technologies, Wilmington, DE, USA).

$B C R$ promoter methylation analysis. To quantitatively measure DNA methylation of the $B C R$ promoter region, bisulfite PCR pyrosequencing was performed. Bisulfitetreated DNA was used for the pyrosequencing analysis as previously described (16). In brief, bisulfite converts cytosine to uracil, but has no effect on methylated cytosine. PCR was performed on the bisulfite-converted DNA for the $B C R$ gene [BCR-F: TTAGGTTGTGAGGTGTGAGGAAT and $B C R-\mathrm{R}$ (bio): biotin-CAAAAACTACTCTCTCTAACAAAACTC]. Streptavidin-sepharose beads (Amersham Biosciences, Uppsala, Sweden) and the Vacuum Prep Tool (Biotage, Uppsala, Sweden) were used to purify the single-stranded biotinylated PCR product. Sequencing primers (BCR-SP1: ATGGAAGGTGTTTTT and BCR-SP2: TGGTGGTTTTTG ATA) were annealed to the purified PCR product and used for a pyrosequencing reaction using the PSQ 96HS system (Biotage). Raw data were analyzed with the allele quantification algorithm using the software provided. The $B C R$ pyrosequencing assay measured the level of DNA methylation of four $\mathrm{CpG}$ sites in the promoter region, and the average methylation level was used for analysis.

Statistical analysis. Variables included for analysis in the study were age, gender, duration of standard dose imatinib, mutation status, cytogenetic response, molecular response, baseline $B C R$ promoter methylation, change in $B C R$ promoter methylation following 6 months of dose escalation and TTFx. 
Table I. Demographics, baseline characteristics and treatment results of the 64 chronic myeloid leukemia patients.

\begin{tabular}{|c|c|c|c|c|}
\hline & $\begin{array}{c}\text { No. of } \\
\text { patients }\end{array}$ & Percentage & Median & Range \\
\hline Age (years) & & & 50 & $20-71$ \\
\hline \multicolumn{5}{|l|}{ Gender } \\
\hline Male & 46 & 71.9 & & \\
\hline Female & 18 & 21.8 & & \\
\hline $\begin{array}{l}\text { Duration of standard dose } \\
\text { imatinib (months) }\end{array}$ & & & 13.9 & $0.6-52.8$ \\
\hline \multicolumn{5}{|l|}{ Baseline cytogenetics } \\
\hline Partial CyR & 29 & 45.3 & & \\
\hline Less than partial CyR & 35 & 54.7 & & \\
\hline \multicolumn{5}{|l|}{ Baseline status } \\
\hline Suboptimal response & 19 & 29.7 & & \\
\hline Treatment failure & 45 & 70.3 & & \\
\hline \multicolumn{5}{|l|}{ Mutation status } \\
\hline Wild-type & 19 & 29.7 & & \\
\hline Mutant $^{\mathrm{a}}$ & 3 & 4.7 & & \\
\hline Unknown & 42 & 65.6 & & \\
\hline \multicolumn{5}{|l|}{$\begin{array}{l}\text { Cytogenetic response } \\
\text { at } 6 \text { months }\end{array}$} \\
\hline Complete CyR & 16 & 25.0 & & \\
\hline Partial CyR & 14 & 21.9 & & \\
\hline Less than partial CyR & 19 & 29.7 & & \\
\hline \multirow{2}{*}{\multicolumn{5}{|c|}{$\begin{array}{l}\text { Cytogenetic response at } \\
12 \text { months }\end{array}$}} \\
\hline & & & & \\
\hline Complete CyR & 17 & 26.6 & & \\
\hline Partial CyR & 11 & 17.2 & & \\
\hline Less than partial CyR & 14 & 21.9 & & \\
\hline \multicolumn{5}{|l|}{ Early molecular responder } \\
\hline Yes & 38 & 59.4 & & \\
\hline No & 19 & 29.7 & & \\
\hline
\end{tabular}

${ }^{a}$ Mutants include F317L and H396R. CyR, cytogenetic response.

Statistical analyses of $2 \times 2$ contingency tables of categorical variables were performed using Pearson's $\chi^{2}$ test or Fisher's exact test, as appropriate. To compare serial values, a generalized linear model with repeated measurements was used. Median durations of TTFx were calculated using the Kaplan-Meier method, and comparisons between the groups were made using log-rank tests. The impact of continuous numeric variables on clinical outcome was calculated using logistic regression and a Cox regression model. A multivariate analysis was performed using a logistic regression model for response and Cox regression models for TTFx. Factors with p-values $<0.1$ in the univariate analysis were examined with multivariate regression models. The statistical tests were twosided with significance defined as $\mathrm{p}<0.05$. All analyses were performed using SPSS for Windows version 12.0 (SPSS Inc.).

\section{Results}

Patient demographics. Characteristics of the patients enrolled in this imatinib dose escalation study were described elsewhere (15). A total of 71 Korean patients from 19 centers were enrolled between 2005 and 2006. Among them, 64 patients were in CP CML. Table I shows the baseline characteristics and treatment results of the $64 \mathrm{CP}$ patients. Of the 64 CP CML patients, 38 (59.4\%) achieved a 50\% reduction in the $B C R-A B L / A B L$ ratio within 6 months following dose escalation (early molecular responder; EMR). Estimated median TTFx of the 64 patients was 27.0 months. Patients who showed a suboptimal response to standard dose imatinib had a longer median TTFx compared to those who showed treatment failure to standard doses of imatinib (not achieved vs. 12.3 months, respectively, $\mathrm{p}=0.023$ ). EMRs achieved $\mathrm{CCyR}$ more frequently at 6 and 12 months $(\mathrm{p}=0.010$ and $\mathrm{p}<0.001$, respectively). Similarly, TTFx of the EMR patients was longer than that of the non-EMR patients (not achieved vs. 11.0 months, $\mathrm{p}<0.001$ ). The baseline $B C R-A B L$ mutation study showed 2 mutants and 26 wild-type patients. For the remaining patients, either the PCR assay did not reveal sufficient cancer cells for inclusion in the study or the patients refused to participate in the mutation study. Specific mutations found included H396R and F317L.

Among the $64 \mathrm{CP}$ patients, 37 patients whose blood samples were available underwent $B C R$ promoter DNA methylation analysis. Patient characteristics of the 37 patients in comparison with the optimal responders and healthy donors are shown in Table II. Median age was 50 years (range 20-71), and the median duration of treatment with the standard dose of imatinib was 14.3 months (range 1.0-52.8). Regarding baseline cytogenetic response, 16 patients exhibited partial cytogenetic response (PCyR), and 21 patients exhibited less than PCyR (sub-PCyR) while on the standard imatinib dose. When the cytogenetic status was considered with respect to treatment duration with the standard imatinib dose, we found that 12 patients were in suboptimal response and 25 patients were in treatment failure. The 2 patients with the $B C R-A B L$ mutants were available for $B C R$ promoter DNA methylation analysis. The patient with the H396R mutation experienced treatment failure at 6.13 months, whereas the patient with the F317L mutation did not experience treatment failure for 18.7 months. The patient with the H396R mutation was EMR, but the patient with the F317L mutation was a non-EMR.

DNA methylation of the $B C R$ promoter was also evaluated in the 29 optimal responders and the 39 healthy controls. Optimal responders included 20 males and 9 females. Median age was 47 years (range 19-68). The age did not differ from the average age of the study population $(\mathrm{p}=0.103)$. The median duration of treatment with the standard dose imatinib was 29.9 months (range 5.8-63.5). The duration of standard dose imatinib was longer in the optimal responders compared to the suboptimal responders $(\mathrm{p}<0.001)$. Healthy controls comprised 20 males and 19 females, with a median age of 25.5 years (range 20-36). This age was significantly lower when compared with the age of the study population $(\mathrm{p}<0.001)$ and the optimal responders $(\mathrm{p}<0.001)$.

$B C R$ promoter methylation analysis in patients who received escalated dose imatinib. The mean methylation level in the 
Table II. Comparison between the 3 study groups that underwent $B C R$ promoter DNA methylation analysis.

\begin{tabular}{lccc}
\hline & $\begin{array}{c}\text { Patients in the dose escalation study } \\
(\mathrm{n}=37)\end{array}$ & $\begin{array}{c}\text { Optimal responders } \\
(\mathrm{n}=29)\end{array}$ & $\begin{array}{c}\text { Healthy controls } \\
(\mathrm{n}=39)\end{array}$ \\
\hline Age, mean (range) in years & $49.2(20-71)$ & $44.8(19-68)$ & $25.5(20-36)$ \\
Gender & & & 0.085 \\
Male & 27 & 20 & 20 \\
Female & 10 & 9 & 20 \\
Duration of standard dose imatinib, & $20.3(1.0-52.8)$ & $33.9(5.8-63.5)$ & NA \\
mean (range) in months & & & 0.002 \\
\end{tabular}

aPost-hoc analysis revealed that age between the optimal responders and the patients in the dose escalation study were not different ( $\mathrm{p}=0.261)$. NA, not applicable.
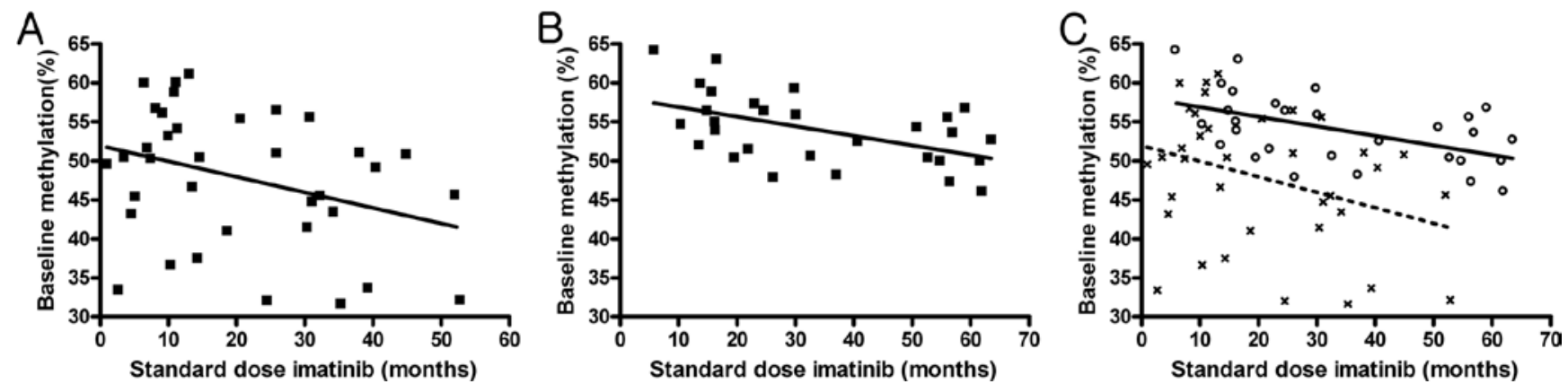

Figure 1. Correlation between the duration of standard dose imatinib and the $B C R$ promoter methylation percentage in two different groups. $B C R$ promoter methylation decreased with a prolonged prior standard dose of imatinib treatment both in the (A) study population and in the (B) optimal responders. The pattern of decrease, however, was significantly different, with a lower decrease and a higher methylation level in the optimal responders (solid line) compared to the (C) study population (dotted line).

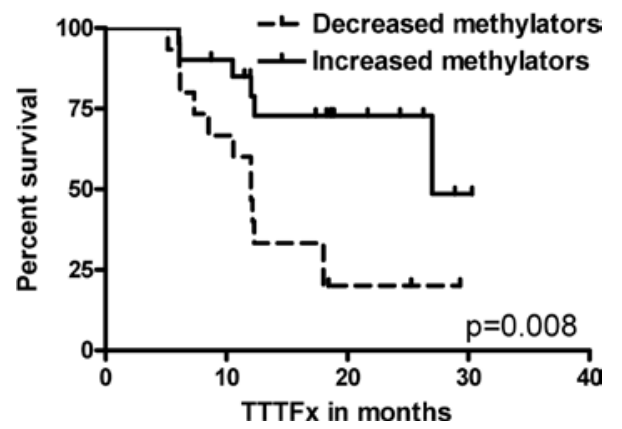

Figure 2. Changes in $B C R$ promoter methylation levels during treatment with escalated dose imatinib and its impact on clinical outcome Following dose escalation, 21 of the 37 patients showed increased methylation (increased methylators) compared with the baseline. Increased methylators (solid line) had a longer TTFx $(\mathrm{p}=0.008)$ compared with the decreased methylators (dotted line).

patients was $47.9 \%$ (range $31.6-61.2 \%$ ) at the time of study enrollment (baseline). Age had an inverse linear correlation with the baseline methylation level ( $\mathrm{p}=0.005)$, and the methylation level was significantly higher in patients $<50$ years of age as compared to the older patients $(\mathrm{p}=0.001)$. Baseline methylation had an inverse linear correlation depending on the treatment with standard imatinib dose. Moreover, baseline methylation decreased with a prolonged duration of the previously administered standard imatinib dose $(\mathrm{p}=0.041)$ (Fig. 1A). No correlation was noted between age and the duration of standard dose imatinib. Baseline methylation levels were significantly higher in patients who were in PCyR at baseline compared to patients in sub-PCyR (mean level 53.3 vs. $43.8 \%$, respectively; $\mathrm{p}=0.001)$. The baseline methylation level did not predict EMR status ( $\mathrm{p}=0.399)$. Baseline methylation levels were inversely correlated to TTFx, with a hazard ratio (HR) of 0.944 [95\% confidence interval (CI), 0.8930.999; $\mathrm{p}=0.044]$.

The mean methylation level at 6 months was $49.8 \%$ (range 31.2-62.2\%). When compared to the baseline, 21 patients exhibited increased methylation levels (increased methylator), and 15 patients exhibited decreased methylation levels (decreased methylator) after receiving dose-escalated imatinib for 6 months. Methylation levels at 6 months also had an inverse linear correlation with age $(p=0.024)$. The methylation level at 6 months exhibited a correlation with EMR status. In EMR patients, methylation levels at 6 months were higher when compared with the non-EMR patients (mean level 52.4 vs. $45.8 \%$, respectively; p=0.046). Finally, methylation levels at 6 months were more strongly correlated to TTFx than baseline methylation levels with a HR of 0.922 (95\% CI, 0.873-0.975; $\mathrm{p}=0.005$ ).

When changes in the BCR DNA methylation levels were considered, increased methylators were predominantly EMR 
Table III. $B C R$ promoter methylation levels according to clinical characteristics $(n=37)$.

\begin{tabular}{|c|c|c|c|c|c|c|c|}
\hline \multirow{2}{*}{ Clinical characteristics } & \multirow{2}{*}{$\begin{array}{r}\text { Baseline } \\
\text { (mean, \%) }\end{array}$} & \multirow{2}{*}{ P-value } & \multirow{2}{*}{$\begin{array}{c}\text { At } 6 \text { months } \\
(\text { mean, } \%)\end{array}$} & \multirow{2}{*}{ P-value } & \multicolumn{2}{|c|}{ Change } & \multirow{2}{*}{ P-value } \\
\hline & & & & & + & - & \\
\hline Age & & 0.001 & & 0.437 & & & 0.735 \\
\hline$\geq 50$ & 43.7 & & 50.5 & & 11 & 7 & \\
\hline$<50$ & 52.3 & & 48.0 & & 10 & 8 & \\
\hline Gender & & 0.415 & & & & & 0.058 \\
\hline Male & 47.2 & & & & 18 & 8 & \\
\hline Female & 49.8 & & & & 3 & 7 & \\
\hline Baseline FISH & & 0.001 & & 0.008 & & & 0.767 \\
\hline PCyR & 53.3 & & 53.9 & & 9 & 6 & \\
\hline Sub-PCyR & 43.8 & & 46.7 & & 11 & 9 & \\
\hline Baseline status & & 0.007 & & 0.005 & & & 1.000 \\
\hline Suboptimal response & 53.3 & & 54.7 & & 6 & 5 & \\
\hline Treatment failure & 45.3 & & 43.7 & & 15 & 10 & \\
\hline Early molecular responder & & 0.399 & & 0.046 & & & 0.041 \\
\hline Yes & 48.9 & & 52.4 & & 16 & 6 & \\
\hline No & 46.3 & & 45.8 & & 5 & 9 & \\
\hline Time to treatment failure (HR) & 0.944 & 0.044 & 0.922 & 0.005 & 0.287 & 1 & 0.008 \\
\hline
\end{tabular}

Table IV. Odds ratio and p-value for EMR status and TTFx in multivariate analysis.

\begin{tabular}{|c|c|c|c|c|c|c|c|c|}
\hline \multirow[b]{3}{*}{ Characteristics } & \multicolumn{4}{|c|}{ EMR achievement } & \multicolumn{4}{|c|}{ TTFx } \\
\hline & \multirow[b]{2}{*}{ OR } & \multicolumn{2}{|c|}{$95 \% \mathrm{CI}$} & \multirow[b]{2}{*}{ P-value } & \multirow[b]{2}{*}{ HR } & \multicolumn{2}{|c|}{$95 \% \mathrm{CI}$} & \multirow[b]{2}{*}{ P-value } \\
\hline & & Low & High & & & Low & High & \\
\hline Baseline status & & & & & & & & 0.388 \\
\hline Treatment failure & 0.595 & 0.088 & 4.001 & 0.593 & 1.858 & 0.455 & 7.588 & \\
\hline Suboptimal response & 1 & & & & 1 & & & \\
\hline Baseline $B C R$ methylation & 1.052 & 0.951 & 1.164 & 0.324 & 0.956 & 0.895 & 1.021 & 0.180 \\
\hline Change in $B C R$ methylation & & & & 0.022 & & & & 0.015 \\
\hline Increase & 6.503 & 1.314 & 32.188 & & 0.294 & 0.110 & 0.786 & \\
\hline Decrease & 1 & & & & 1 & & & \\
\hline
\end{tabular}

OR, odds ratio; EMR, early molecular responder; TTFx, treatment failure; CI, confidence interval; HR, hazard ratio.

patients $(\mathrm{p}=0.041)$. Increased methylators had a longer TTFX compared to decreased methylators (median TTFx 27.0 vs. 12.0 months, $\mathrm{p}=0.008$ ) (Fig. 2). The results are noted in Table III.

When multivariate analysis was performed considering the baseline cytogenetic response with duration of standard dose imatinib, baseline $B C R$ promoter DNA methylation levels and changes in $B C R$ methylation levels after 6 months, only the increase noted in the $B C R$ promoter DNA methylation level following dose escalation therapy was an independent predictor for achievement of EMR [odds ratio (OR), 0.154; $\mathrm{p}=0.022]$ and TTFx (HR, 0.294; $\mathrm{p}=0.015$ ) (Table IV).
Thus, both baseline and 6-month $B C R$ promoter DNA methylation levels were higher in younger patients and in patients who exhibited a more favorable response to the standard imatinib dose. However, only a change in the $B C R$ promoter DNA methylation level following dose escalation therapy was correlated to EMR status and TTFx.

Evaluation of BCR promoter methylation in optimal responders and healthy controls. The mean $B C R$ promoter DNA methylation level of the optimal responders was $54.0 \%$ (range 46.1-64.2\%). The optimal responders had significantly higher methylation levels when compared with the baseline 


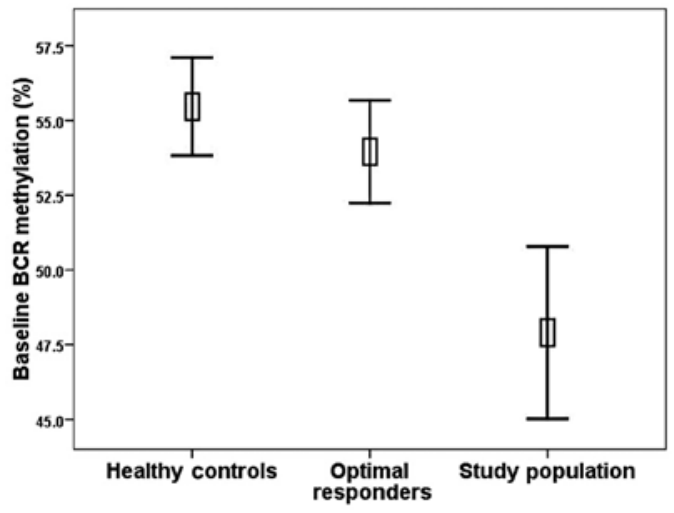

Figure 3. A box-plot showing $B C R$ promoter methylation levels in the healthy controls, optimal responders and the study population. The box and error bars indicate the mean and the $95 \%$ confidence interval. The $B C R$ promoter methylation level was significantly higher in the healthy controls and the optimal responders compared with the study population. No significant difference in methylation levels between the healthy controls and the optimal responders was noted

methylation levels in the study patients $(\mathrm{p}=0.001)$ (Fig. 3). $B C R$ promoter DNA methylation again had an inverse linear correlation with age $(\mathrm{p}=0.040)$ and duration of standard dose imatinib ( $\mathrm{p}=0.004)$ (Fig. 1B). However, the pattern of the decrease in methylation levels in correlation with the duration of imatinib use was significantly different between patients who received dose-escalated imatinib and the optimal responders $(\mathrm{p}=0.001)$ (Fig. 1C).

Regarding the healthy controls, the mean $B C R$ promoter DNA methylation level was $55.5 \%$ (40.0-62.0\%). The methylation levels of the healthy donors were significantly higher when compared with baseline methylation levels in the study patients $(\mathrm{p}<0.001)$. In contrast, no difference was noted in methylation levels between the healthy donors and optimal responders (Fig. 3). The methylation levels did not correlate with age.

Thus, $B C R$ methylation levels were higher in the patients who were likely to have a lower disease burden and in those with a more favorable response to imatinib. However, no difference was found between patients with CML who had an optimal response and those without CML.

\section{Discussion}

The main purpose of the present study was i) to reveal the role of the $B C R$ promoter in the transcriptional control of the $B C R-A B L$ fusion gene, and ii) to investigate epigenetic predictive markers for response and long-term outcome of imatinib treatment. For this purpose, we analyzed the clinical implication of $B C R$ promoter DNA methylation.

The first analysis focused on CP CML patients who received dose-escalated imatinib treatment for suboptimal response. In the first analysis, high baseline $B C R$ promoter DNA methylation levels were correlated with young age, low leukemic burden at study enrollment and a more favorable response to the standard imatinib dose. In contrast, $B C R$ promoter DNA methylation at 6 months had no correlation with age and a weaker correlation with baseline disease burden than $B C R$ promoter DNA methylation at baseline.
The results indicate that the $B C R$ promoter DNA methylation level was affected by the dose escalation treatment. From a therapeutic viewpoint, major end points of the analysis in this study included achievement of EMR, defined as those patients who achieved a $50 \%$ reduction in the $B C R-A B L / A B L$ gene ratio within 6 months, and TTFx. We previously showed that EMR is an ideal surrogate marker for long-term disease control in these patients (15). For the two endpoints, the single independent factor for favorable outcome was an increase in $B C R$ promoter DNA methylation following the imatinib dose escalation treatment. The above results strongly suggest that the $B C R$ promoter DNA methylation status correlates well, not only with disease status, but also with response to imatinib.

In the second analysis, we compared $B C R$ promoter DNA methylation among three distinct groups of subjects. In the this second analysis, lower $B C R$ promoter DNA methylation levels were observed in patients who received dose-escalated imatinib compared to the optimal responders and the healthy controls. Although $B C R$ promoter DNA methylation decreased with age, no significant difference was noted between the optimal responders and healthy controls (despite the age difference between the two groups), indicating that disease burden is the main factor affecting the level of $B C R$ promoter DNA methylation. These findings collectively suggest that $B C R$ promoter DNA methylation is correlated with disease status.

We measured the entire level of $B C R$ promoter DNA methylation. In other words, the level of $B C R$ promoter DNA methylation in our study included both the BCR promoter methylation of the $B C R$ gene without fusion and that of the $B C R-A B L$ fusion gene. Since we lacked information regarding the difference between the $B C R$ and $B C R-A B L$ fusion genes at the $B C R$ promoter methylation level, it is plausible to make two assumptions concerning the underlying mechanism of these phenomena according to this difference.

If we assume that the $B C R$ promoter methylation level of the $B C R-A B L$ fusion and $B C R$ genes are the same, then the phenomena suggest that the progression of CML involves decreased methylation of the $B C R$ promoter and this decreased methylation in CML patients is restored upon imatinib treatment in patients who benefit from the drug. If this is viable, these results suggest a possible role of methylating agents in CML.

On the other hand, if we assume that the $B C R$ promoter methylation level of the $B C R-A B L$ fusion gene is lower than that of the $B C R$ gene, then the phenomena may be interpreted in the followin manner: The change in $B C R$ promoter DNA methylation can be a simple reflection of the change in the ratio of $B C R-A B L$ to $B C R$ cells or the stem cell or population of blood cells upon treatment. Thus, high levels of $B C R$ promoter methylation represent normal cells whereas low levels are CML cells, and the changes noted represent ratios of normal to CML cells. Determination of the difference in the $B C R$ promoter methylation level between the $B C R$ and $B C R-A B L$ fusion genes using new techniques can establish which explanation is accurate.

Decreased $B C R$ promoter methylation with prolonged use of standard dose imatinib observed in the optimal responders reveals another finding. Assuming that complete $\mathrm{CyR}$ at the time of sampling of the optimal responders 
reflects a negligible leukemic burden, the phenomenon suggests that $B C R$ promoter methylation of the $B C R$ gene is affected by imatinib treatment. Moreover, the significant difference in the pattern of decrease in $B C R$ promoter methylation levels between the patients who received dose-escalated imatinib and the optimal responders is another significant finding. The clinical significance of this finding is unknown; however, it may be related to a mechanism underlying imatinib resistance.

Finally, the mean $B C R$ promoter DNA methylation level was $55.5 \%$ for healthy controls. Although the accurate normal reference of $B C R$ promoter DNA methylation may be different according to age or ethnicity, defining the reference value of $B C R$ promoter DNA methylation in the normal population is crucial for further application of the $B C R$ promoter DNA methylation.

In conclusion, methylation of the $B C R$ promoter correlated well with disease status upon treatment with imatinib, and an increase in $B C R$ promoter methylation indicated a favorable outcome. BCR promoter DNA methylation decreased with prolonged imatinib (400 $\mathrm{mg} /$ day) use both in the optimal responders and in the patients who failed to achieve optimal responses, although the patterns of decrease were different.

\section{Acknowledgements}

This study was supported by a grant from the Korea Health 21 R\&D Project, Ministry of Health \& Welfare, Republic of Korea (0405-BC02-0604-0004). We especially thank all members of the Korean CML Working Party.

\section{References}

1. Goldman JM and Melo JV: BCR-ABL in chronic myelogenous leukemia - how does it work? Acta Haematol 119: 212-217, 2008.

2. Ren R: Mechanisms of BCR-ABL in the pathogenesis of chronic myelogenous leukaemia. Nat Rev Cancer 5: 172-183, 2005.

3. Wen ST and Van Etten RA: The PAG gene product, a stressinduced protein with antioxidant properties, is an Abl SH3-binding protein and a physiological inhibitor of c-Abl tyrosine kinase activity. Genes Dev 11: 2456-2467, 1997.
4. McWhirter JR, Galasso DL and Wang JY: A coiled-coil oligomerization domain of Bcr is essential for the transforming function of Bcr-Abl oncoproteins. Mol Cell Biol 13: 7587-7595, 1993.

5. Pendergast AM, Muller AJ, Havlik MH, et al: BCR sequences essential for transformation by the BCR-ABL oncogene bind to the ABL SH2 regulatory domain in a non-phosphotyrosinedependent manner. Cell 66: 161-171, 1991.

6. Issa JP, Kantarjian H, Mohan A, et al: Methylation of the ABL1 promoter in chronic myelogenous leukemia: lack of prognostic significance. Blood 93: 2075-2080, 1999.

7. Sun B, Jiang G, Zaydan MA, et al: ABL1 promoter methylation can exist independently of BCR-ABL transcription in chronic myeloid leukemia hematopoietic progenitors. Cancer Res 61: 6931-6937, 2001.

8. Zion M, Ben-Yehuda D, Avraham A, et al: Progressive de novo DNA methylation at the bcr-abl locus in the course of chronic myelogenous leukemia. Proc Natl Acad Sci USA 91: 10722-10726, 1994.

9. Shtivelman E, Lifshitz B, Gale RP, et al: Fused transcript of abl and ber genes in chronic myelogenous leukaemia. Nature 315: 550-554, 1985.

10. Jiang G, Yang F, Li M, et al: Imatinib (ST1571) provides only limited selectivity for CML cells and treatment might be complicated by silent BCR-ABL genes. Cancer Biol Ther 2: 103-108, 2003.

11. Baccarani M, Saglio G, Goldman J, et al: Evolving concepts in the management of chronic myeloid leukemia: recommendations from an expert panel on behalf of the European LeukemiaNet. Blood 108: 1809-1820, 2006.

12. Hughes T: ABL kinase inhibitor therapy for CML: baseline assessments and response monitoring. Hematology Am Soc Hematol Educ Program: 211-218, 2006.

13. Hochhaus A and Hughes T: Clinical resistance to imatinib: mechanisms and implications. Hematol Oncol Clin North Am 18: 641-656, 2004.

14. Druker BJ, Guilhot F, O'Brien SG, et al: Five-year follow-up of patients receiving imatinib for chronic myeloid leukemia. N Engl J Med 355: 2408-2417, 2006.

15. Koh Y, Kim I, Yoon SS, et al: Phase IV study evaluating efficacy of escalated dose of imatinib in chronic myeloid leukemia patients showing suboptimal response to standard dose imatinib. Ann Hematol 89: 725-731, 2010.

16. Yang AS, Estecio MR, Doshi K, et al: A simple method for estimating global DNA methylation using bisulfite PCR of repetitive DNA elements. Nucleic Acids Res 32: e38, 2004. 